\title{
Global Competency: Are Engineering Students Ready?
}

\section{Dr. Steven H. Billis, New York Institute of Technology}

Steven H. Billis, Ph.D, is professor of Electrical and Computer Engineering of the School of Engineering and Computing Sciences (SoECS) at New York Institute of Technology. He is also the Director of Assessment and Planning for the SoECS and in this regard responsible for accreditation and reaccreditation of the School's programs. he earned his Ph.D. from the Polytechnic Instiute of Brooklyn in 1972 in the area of Quantum Electronics. His present area of expertise is digital design.

\section{Dr. Nada Marie Anid, New York Institute of Technology}

Nada Marie Anid, Ph.D., is the first female dean of NYIT's School of Engineering and Computing Sciences (SoECS). In this role, she oversees 77 engineering and computing sciences faculty members and approximately 1,700 graduate and undergraduate students at campuses located in Manhattan and Old Westbury, N.Y., the Middle East, and China. Her expertise is in Industry-academic partnerships; Entrepreneurship and Innovation; Emerging Technologies; Sustainability; Global Engineering Education; STEM K-12 Outreach.

Dr. Anid embraces NYIT's forward-thinking and applications-oriented mission and is working on several strategic partnerships between the School of Engineering and the public and private sector, including the creation of the School's first Entrepreneurship and Technology Innovation Center (ETIC) and its three labs in the critical areas of IT \& Cyber Security, Bio-engineering and Health, and Energy and Green Technologies. She is a board member of several organizations including the Greater Long Island Clean Cities Coalition (GLICC), LISTnet, the Institute for Sustainability (IfS) of the American Institute for Chemical Engineers (AIChE), the Riverdale Conservancy, and the Environment and Public Health Network of Chinese Students and Scholars (ENCSS). Dr. Anid is a Program Evaluator for the Engineering Accreditation Commission of the Accreditation Board of Engineering and Technology (ABET), and holds leadership positions in AIChE, the New York Academy of Sciences, the American Society for Engineering Education (ASEE), the US Deans Engineering Council and its Public Policy Committee, among others. She earned her Ph.D. in environmental engineering from the University of Michigan (Ann Arbor), and bachelor's and master's degrees in chemical engineering from the Royal Institute of Technology (KTH-Stockholm). Prior to joining NYIT, she was chair and graduate program director of the Chemical Engineering Department at Manhattan College.

\section{Dr. Marta A Panero, New York Institute of Technology}

Dr Panero is Director for Strategic Partnerships for the School of Engineering and Computing Sciences at New York Institute of Technology. 


\title{
Global Competency: Are Engineering Students Ready?
}

\begin{abstract}
:
Increasingly, successful entry into the engineering and technology professions requires students to have "global competency" or significant cross-cultural skills, in order for them to collaborate effectively with colleagues from diverse backgrounds.

In 2005, the New York Institute of Technology (NYIT) initiated a Master Strategic Plan that established overarching strategies to guide the university as it embarked on its next quarter century of operations. A key initiative of the Master Strategic Plan was revisiting NY IT's core curriculum, created to provide students with an outcomes-oriented education that would prepare them for today's workforce and easy entry into the global market.
\end{abstract}

The "Discovery Core" focuses on specific foundations that are necessary for success in every profession, including skills in communications, critical and analytical thinking, an interdisciplinary mindset, ethical and civic engagement, knowledge of the arts and sciences. One of its main learning criteria is a global perspective where "students can identify interdependencies among cultures and are able to collaborate effectively, and participate in global social and business settings". All academic departments at NYIT are expected to reinforce these core competencies in the courses specific to their programs.

In engineering, global competency has never been an explicit ABET Student Outcome (SO) for any of the engineering programs, except in outcome (h): "The broad education necessary to understand the impact of engineering solutions in a global and societal context”.

In a paper presented at the 2012 ASEE PSW Conference, Dianne J. DeTurris ${ }^{1}$, took a broader interpretation of the familiar ABET SOs, "a to k", to allow for an implicit recognition of this goal, when taking into account "what forms of knowledge, sets of capabilities and learning experiences are needed to prepare engineering students for work" 2

This paper expands on the work of DeTurris and links the global perspective learning criterion of the Discovery Core Curriculum to the ABET engineering SOs as well as to intercultural competency metrics, and illustrates the assessment of this learning criterion and the performance criteria of the SOs. It also establishes a set of “Appropriate Performance Tasks, (APTs)” in specific courses to foster cross-cultural interactions among students in order to assess global competency. The paper also covers rubrics used for this purpose.

\section{Introduction:}

NYIT is a non-profit independent, private institution of higher education. It has 13,000 students attending its New York and global campuses, including in Abu Dhabi, UAE, Nanjing, China, and Vancouver, Canada.

Under the leadership of its President, NYIT is guided by its mission to provide career- oriented professional education, offer access to opportunity to all qualified students, and support applications-oriented research that benefits the larger world. Its students represent nearly all 50 U.S. states and 109 countries, with 1400 international students at the New York campuses, the 
majority of whom are School of Engineering and Computing Sciences (SoECS) students.

Following the creation of a Master Strategic Plan, a key initiative revisited the university's core curriculum which resides in the College of Arts and Sciences.

The new Discovery Core Curriculum utilizes a progressive approach that allows students to master core competencies throughout their undergraduate career. The Core focuses on specific foundations that are necessary for success in every profession and includes skills in communications, critical and analytical thinking, an interdisciplinary mindset, ethical and civic engagement, a global perspective, and knowledge of the arts and sciences. The new Core is focused on introducing and fostering these overall core competencies so that students will be able to meet the critical needs of their future employers.

\section{Relationship of Global Competency and ABET Student Outcomes:}

The implementation of the Discovery Core presented the SoECS with the opportunity to create a new core seminar IENG 400 "Technology and Global Issues" to ensure that the following ABET Student Outcomes (SOs) ${ }^{3}$ were met: an understanding of professional and ethical responsibility ( $f$ ); the broad education necessary to understand the impact of technical solutions in a global, economic, environmental, and societal context (h), and a knowledge of contemporary issues $(j)$. It also offered an opportunity to focus on the following elements of a global perspective:

- demonstrate a familiarity with current trends in a variety of technical fields and contemporary issues inside/outside their own discipline and the historical aspects associated with technical solutions. Discuss, and summarize, their impacts at global, national, state and local levels. (SOs h, $\mathbf{j}$ )

- evaluate solutions, or scenarios using a series of different measures- e.g., economic, quality of life; number of individuals affected; political ramifications; etc. (SO h)

- develop and articulate a personal perspective on both the importance and dangers of science in today's world. (SO j)

- demonstrate an understanding of the ethical and moral aspects of the issues and their cultural associations. (SO f)

The SoECS requires all of its students to take IENG 400.

While it is true, as Dianne J. DeTurris pointed out, that only one ABET Student Outcome (i.e., "h") specifically mentions the word "global", it should be clear from the above discussion that in addition to the economic, environmental and societal contexts of SO "h"; SOs "f, $\mathbf{j}$ ” are also components of a contemporary global perspective. However, several other ABET SOs ${ }^{3}$ “ “c, d, f, $\mathbf{j}$, and k” lend themselves to an interpretation involving global issues as follows:

- c: "an ability to design a system, component or process to meet desired needs within realistic constraints such as economic, environmental, social, political, ethical, health and safety, manufacturability and sustainability”. The realistic constraints are often influenced by a country's culture, resources and government

- d: "an ability to function on multidisciplinary teams". Valuing other team members' contributions and perspectives. 
- f: "an understanding of professional and ethical responsibility". Ethical issues are often very different across cultures.

- $\mathbf{j}$ : “a knowledge of contemporary issues". Engineering solutions are world-wide solutions and very much a function of contemporary issues.

- k: "an ability to use the techniques, skills, and modern engineering tools necessary for engineering practice". The modern engineering tools and techniques necessary for engineering practice differ world-wide and will therefore determine the skills of co-workers from other countries.

In addition, and in an effort to deepen students' global perspective through direct exposure, the SoECS is planning a number of international exchange programs, beyond the ongoing opportunities to study at our global campuses (i.e., Nanjing, Abu-Dhabi, Vancouver). For example, the School has already signed a Memorandum of Understanding with Instituto Tecnologico (InTEC) in the Dominican Republic, to foster academic collaborations and student exchanges. Intec and the university, along with six other Latin American universities are members of the U.S. State Department-sponsored "Pathways to Cleaner Production in the Americas" ${ }^{\prime 4}$ initiative, and the university is in the process of signing additional MoUs with these partners to broaden the range of opportunities to study abroad offered to our students. Furthermore, NYIT will leverage a U.S. Department of State initiative, 100K Strong in the Americas, to partner with additional Latin American universities, in an effort to "foster regionwide prosperity through greater international exchange of students, who are our future leaders and innovators." ${ }^{\circ}$

\section{Implementation:}

For the SoECS, the core outcome of global competency is defined as:

"Students can identify interdependencies among cultures and are able to collaborate effectively, participating in social and business settings globally".

This implies that at the time of graduation students will:

- Recognize the impact of the global interconnectedness of issues, processes, trends, and systems on their academic specializations and worldviews. (SOs "h, j")

- Describe a complex global issue from multiple cultural perspectives and explain how those perspectives affect the treatment of the issue. (SOs "h, j")

- Employ effective and appropriate interaction and teamwork with people of different nationalities and cultures, demonstrating respect for social, cultural, and linguistic diversity (SOs “c, d")

In view of the above Learning Outcomes (LOs), to ensure global competency the Electrical and Computer Engineering (ECE) department concentrates on assessing ABET SOs c, d, f, h, and j.

\section{II.a. Student Outcome (f ) "an understanding of professional and ethical responsibility"}

Students need to understand that ethics is a complex subject that has occupied some of the greatest thinkers for thousands of years. Basically, ethics is the study of "what it means to do the 
right thing”. A related debate is how to view ethical rules - as fundamental and universal, like the laws of science or as rules that provide a framework for interacting with other people in a productive way.

Moreover, from a global perspective, ethical rules differ across different cultures. In some countries it is considered a common business practice to offer bribes or kickbacks, whereas in the U.S. this practice is illegal and unethical. Is one culture’s "bribe” just another culture's "lobbying"? The "bribe" is considered unlawful, whereas the lobbyist is working in a legally recognized manner as long as s/he does not transfer money to gain access to power. Note that ethics is not law, and the role of money in politics has consequences that may serve very narrow interests with little regard for the wider public's interests.

The planned study-abroad programs will expose our students to different cultures' ethical rules and provide an opportunity for healthy debates with local students about diverse perspectives and ways of conducting business in other countries.

To provide ECE students with a curricular engineering education that will give them a global perspective to answer questions like those above, the department considered:

- creating a required course in engineering ethics, which is the model employed at Texas A \& M University,

- an across-the-curriculum initiative as the University of Michigan's engineering college, and

- numerous elective courses in engineering ethics at various institutions, and adopted an across-the-curriculum approach which seeks to address the limitations of the required course model by spreading engineering ethics instruction throughout the engineering curriculum, e.g., in introduction to engineering courses, sophomore engineering science courses, junior discipline-based courses, and senior design experiences.

As a result, the ECE program took the following steps to satisfy this outcome:

II.a.1. The assignment of 'Ethical Decision Making Scenarios' in the freshman course ETCS 105 "Career Discovery"

II.a.2. students are required to enroll in several specific 'Discovery Core Curriculum' courses with "Ethics” content:

\section{ICLT 302, “Strange Creations: Literature, Intelligent Technology and Ethics”,}

This course examines literary representations of artificial, intelligent servants, such as robots, androids, computer networks, and human replicates. The course also discusses literature in which artificial humanoids are central figures and explores how these stories represent various views of the appropriate bounds for humankind's intellectual and scientific ambition. 


\section{ICLT 303, “On the Visionary Frontier: Science Fiction and Its Cultural Significance”}

Science fiction uses various concepts to examine and comment on contemporary society. Science fiction engages a range of cultural and social issues, such as the nature of science and scientific exploration, science and ethics, scientific dystopia, technological apocalypse, relationships between faith and science, cybernetics and human identity, medical ethics, and nanotechnology.

\section{ICPH 304, "Ethics and Social Philosophy”}

The aims of this seminar in ethics are threefold: a) to explore and analyze critically the chief historical and contemporary theories of morality and the "good life;" b) to study the philosophical underpinnings of these theories in the works of the great philosophers; to discover the relevance of ethical theories to the understanding and adjudication of social and personal moral conflicts, and to the conduct of life.

\section{ICPH 306, “Bioethics”}

This seminar that introduces students to the field of bioethics- the study of ethical issues involving the biomedical and life sciences. The course includes readings of moral theories in philosophy and uses these concepts as a framework to examine key issues in bioethics, as well as contemporary debates prompted by emerging technologies.

II.a.3. To continue the across-the-curriculum approach, several of the required engineering and computer science courses incorporate an Ethics case-study, module, or homework assignments into the course outline. The case studies and modules are selected by the faculty from the NAE's Online Ethics Center (OEC) ${ }^{6}$

\section{II.b. Student Outcome ( $\mathrm{h}$ ): the broad education necessary to understand the impact of} engineering solutions in a global, economic, environmental, and societal context

And Student Outcome ( $\mathrm{j}$ ): a knowledge of contemporary issues

As mentioned previously, the university's enrollment figures indicate that international students represent $12 \%$ of our domestic student body, with the majority of these students enrolled in the SoECS' programs. As a result, the course IENG 400 - Technology and Global Issues, which all students of the SoECS are required to take, provides an opportunity for our technology students to directly engage in cross-cultural interactions with people from culturally diverse backgrounds to broaden their perspectives and avoid cultural imposition.

For example, in discussing the issue "Should DDT Be Banned Worldwide?" the questions:

- Do the risks of DDT to the environment outweigh the risks of malaria (1-3 million deaths per year, and 2.5 billion people at risk)?

- Who should be making this decision for poor developing countries...they themselves or an outside party?

- Should DDT be banned before alternatives are in place and known to work? 
will provoke very different responses from poor and developing nations and the highly developed nations of Europe and North America. Furthermore, it is not a decision that can be made by each country independently, since different responses have important consequences to the global economy.

More importantly, it is often the case that the issue "Should Society Act Now to Prevent Climate Change?" will raise very different responses from the developed and underdeveloped nations and even among the developed nations themselves.

The cross-cultural interactions that take place in IENG 400, “Technology and Global Issues” demonstrate that cultural competence is an ongoing process in which global engineers and technologists have to continuously strive to achieve the ability to understand the cultural context of the environment in which they work.

To be effective, global engineers and technologists must appreciate the many factors that differentiate cultural perspectives, "such as time orientation, power, individualism, competitiveness, and thinking styles" regarding such things as status, formality, saving face, directness, the meaning of "yes”, nonverbal cues, etc. ${ }^{6}$

Moreover, the engagement of partner universities (e.g. in Latin America) and study abroad programs, will expose our engineering students to other countries' economic, environmental and societal contexts and encourage them to develop appropriate and contextual solutions to local problems given existing constrains.

\section{II.c. Student Outcome ( d ): an ability to function on multi-disciplinary teams}

The students in the ECE program have several stand-alone required laboratory courses EENG 275, 315, 360, and 403, Electronics Laboratories I, II, III, IV respectively in which they work in teams to complete the lab exercises. To ensure compliance with the "nature of team work", the following have been instituted:

- An "ECE Team Guidelines" document is distributed to all students in the ECE lab sequence (see Appendix A).

- A “Teamwork Rubric Template”, used by the “Lab Team Captain” at least five times during the semester, to document the nature of the teamwork through the contribution of each team member to the project (see Appendix B).

It is clear that here is where the students learn some of the most important aspects of a global perspective, (i.e., to employ effective and appropriate interaction and teamwork with people), as illustrated by the attached evaluation form. Even in the absence of team members with different nationalities and cultures, demonstrating respect for one another in the labs reinforces that behavior. When they take IENG 400 "Technology and Global Issues" or their Senior Capstone Design Projects I and II, they have learned to respect ethical, social, cultural, and linguistic diversity. These learning outcomes will be most evident in the case of students participating in the study abroad experiences, who will benefit from intensive cultural and language immersion programs. 
II.d. Student Outcome ( c ): an ability to design a system, component, or process to meet desired needs within realistic constraints such as economic, environmental, social, political, ethical, health and safety, manufacturability, and sustainability

In keeping with the major design experience required in the capstone sequence EENG 489, 491, the final project report requires student teams to consider their designs within realistic constraints and any ethical issues with regard to product safety, disposal, regulation, etc. and the outcome of a global perspective. To foster cross-cultural interactions/global competency students are asked to consider the following questions in analyzing the societal and ethical implications of their design projects:

1. What is the effect of the project on natural resources?

2. What are the raw materials this project would consume? their availability. the long term impact of their use on the environment. the waste generated by production. is the product recyclable? how do we dispose of this product? should we hold some natural resources in reserve for future generations?

3. Who will be affected by this product and how?

4. Is the development of this product safe?

5. Does the use of this product pose any safety issues and if so what are they?

6. Is the development of this product ethical? does it compete with existing ones in an unfair manner?( reverse engineering.) does it infringe on any existing patents?

does it use existing software in an unethical way?

7. What is the risk to the consumer who uses your product?

8. What is your and the manufacturer's potential liability?

9. Is the product economically feasible and is the design cost-effective?

The above questions are at the heart of the "Pathways to Cleaner Production in the Americas" of which NYIT is a coordinating partner. This initiative promotes a Collaborative Approach to Education for Sustainable Industrial Development and "aims to strengthen the preparation of young professionals for careers related to cleaner production, energy efficiency and sustainable industrial development, as well as to improve the economic and environmental performance of micro, small and medium enterprises (MSMEs) by fostering closer interactions between industry and academia on these topics" 4

\section{III: The Process}

For each of the fall and spring semesters, and for each course he/she teaches, the ECE faculty member is required to submit a Faculty Course Assessment Report (FCAR). The FCAR requires each faculty member to:

- $\quad$ identify course specific learning outcomes (LO's) for his/her course and to establish appropriate performance tasks (APTs) with appropriate documentation to assess to what extent the learning outcomes are being met. These APTs may be 
quizzes, exam questions, reports, projects, presentations, etc. Each student's APT is then scored with the method shown below to create an "EGMU"1 vector for that specific learning outcome and a corresponding assessment metric (see Appendix C).

- $\quad$ satisfy a minimum set of Student Outcomes (SOs) for his/her course as established by the department. This is accomplished by using a subset of the appropriate performance tasks (APT's) used to satisfy the LOs.

- $\quad$ show which part of each APT is being used to form a metric for the student outcome with appropriate documentation.

These course-embedded assessments serve as primary tools to determine student outcome achievement and afford a direct link between learning outcomes and student outcomes as one aspect of curriculum change.

The data from FCARs are then evaluated at the spring Faculty Assessment meetings. At these meetings all full-time faculty members and those regular part-time faculty members wishing to participate, identify and propose strategies to improve ABET Student Outcomes and, hence, our program educational objectives through course work. The department has determined that the minimum level of quality to produce graduates that will ultimately achieve its Program Educational Objectives is an EGMU score of 1.5 for each ABET student outcome. ${ }^{2}$ While many courses may satisfy a particular ABET outcome, the assessment committee has selected a subset of these courses that it finds most appropriate to determine the minimum metric for each outcome.

The recommendations of the assessment committee meetings are generally of two types. One set of recommendations can be implemented solely through the faculty member making internal changes to the courses (i.e. textbook changes, pedagogical changes). The other set of recommendations would need to be forwarded to the curriculum committees of the School of Engineering and Computing Sciences and then to the Academic Senate for adoption (i.e. new course, prerequisite/co-requisite changes, catalog description). We have found that each of our assessment tools must be used in conjunction with one another if we are to undertake changes that are meaningful. See Appendix D - "Rubrics for ABET Student Outcomes c, d, f, h, j, k.”

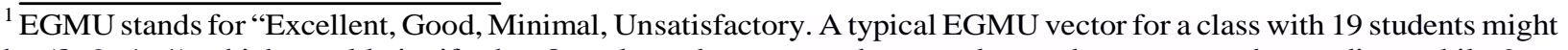
be $(8,9,1,1)$ which would signify that 8 students demonstrated a complete and accurate understanding, while 9 students applied appropriate strategies etc. The average score in this case being 43/19 = 2.26 which is Good.

${ }^{2}$ This score of 1.5 was chosen by the department because in the EGMU scoring it falls midway between the Minimal and Good indicators and therefore represents what a student would need in order to satisfy the requirements for graduation. (If each of the EGMU scores is adjusted to correspond to the grade points associated with A, B, C, D, a 1.5 is a C.)
} 


\section{Results:}

From the previous discussion it is apparent that the ECE department believes that the courses that are strongly linked to the LOs of intercultural and global competency are:

1. ETCS 105 “Career Discovery”: ABET SO “d, f ”, through ethical scenarios which aim to increase our students' tolerance of ambiguity and team projects where working in teams is expected to:

- $\quad$ expose students to alternative perspectives,

- remain non-judgmental when disagreeing with others and

- seek conflict resolution.

As all ECE students are required to take ETCS 105, this course provided the department with the opportunity to determine their level of intercultural and global competency in their freshman year.

The current emphasis on measuring intercultural competence has inspired a large number of assessment instruments. These instruments generally address a variety of needs including outcomes assessment and program evaluation.

The survey questions in Table 1 below were generated from our examination of the list of some of the most frequently used assessment tools ${ }^{7,8,9,10}$, and were administered during the first week of the semester as a pretest and were intended to measure their global competency with respect to:

1. tolerance of ambiguity,

2. behavioral flexibility,

3 . respect for otherness and

4. capacity for empathy.

The same survey was administered at the end of the semester.

Table 1: Global Competency Self-evaluation $\begin{array}{lllll}0 & 1 & 2 & 3 & 4\end{array}$

\begin{tabular}{|c|l|l|l|l|l|l|}
\hline & & $\begin{array}{l}\text { Strongly } \\
\text { disagree }\end{array}$ & $\begin{array}{l}\text { Slightly } \\
\text { disagree }\end{array}$ & $\begin{array}{l}\text { Un- } \\
\text { decided }\end{array}$ & $\begin{array}{l}\text { Slightly } \\
\text { agree }\end{array}$ & $\begin{array}{l}\text { Strongly } \\
\text { agree }\end{array}$ \\
\hline 1 & $\begin{array}{r}\text { I find unexpected and unfamiliar } \\
\text { situations } \\
\text { - enjoyable }\end{array}$ & & & & \\
\hline 3 & $\begin{array}{r}\text { I help other members of the group solve } \\
\text { problems in ways that appeal to the other } \\
\text { group members. }\end{array}$ & & & & & \\
\hline 4 & $\begin{array}{l}\text { I clearly state my position when a problem } \\
\text { occurs by criticism. }\end{array}$ & & & & & \\
\hline & $\begin{array}{l}\text { I adapt my working approach with others } \\
\text { to avoid conflicts }\end{array}$ & & & & & \\
\hline
\end{tabular}




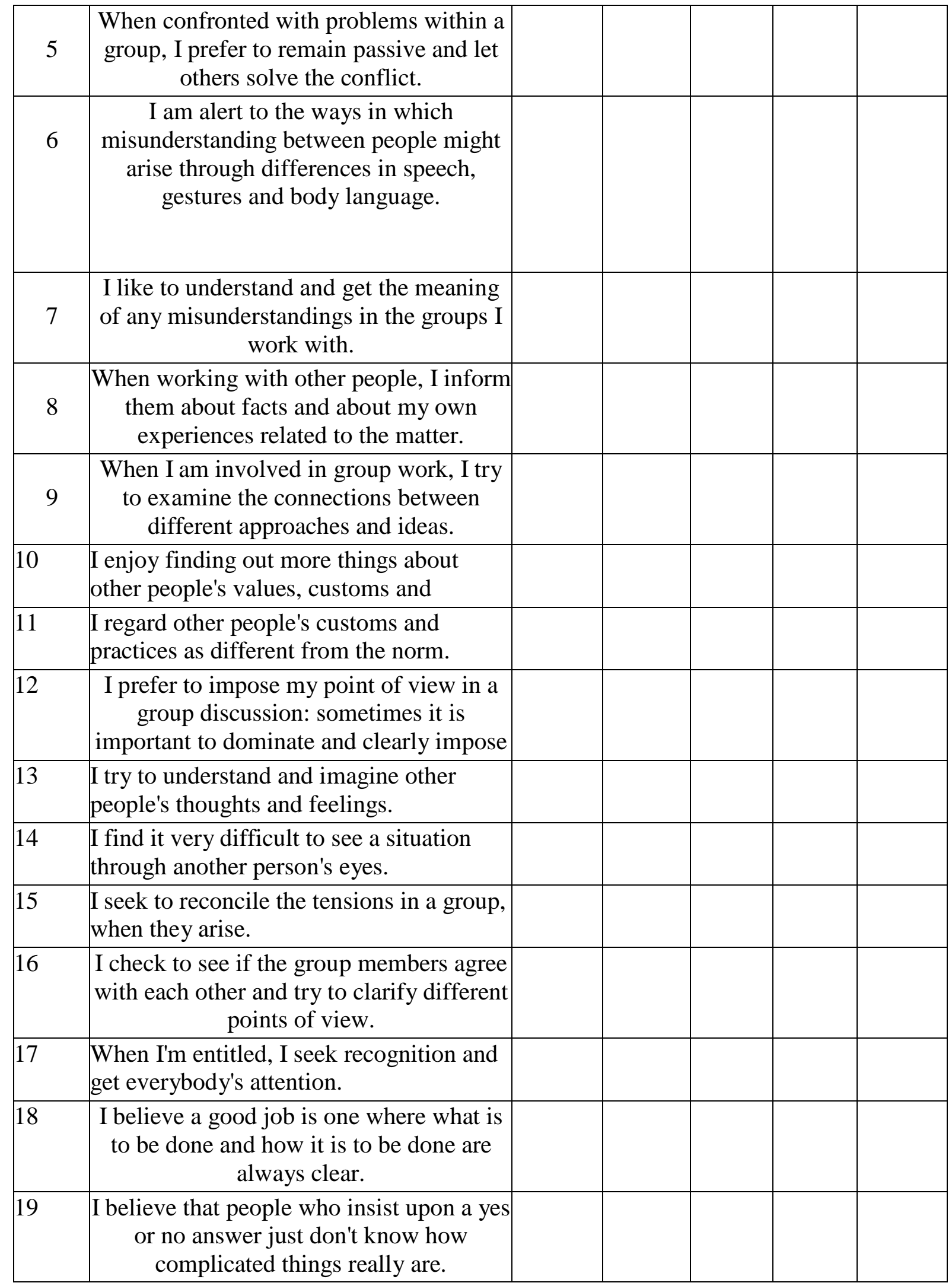

A review of the questions of the survey indicates as shown in Table 2 below, the following relationship between the questions of the survey and a student's intercultural sensitivity. 
Table 2. Survey Questions Indicative of Student Attitudes and Behavior

\begin{tabular}{|c|c|}
\hline Survey Questions & Student Attitudes \& Behavior \\
\hline $1,3,6,7,9,12,17,18,19$ & "tolerance for ambiguity" \\
\hline $4,5,9,15,17$ & "behavioral flexibility" \\
\hline $2,5,6,12,15,16,17$ & "respect for otherness" \\
\hline $6,7,9,10,11,12,13,14$ & "capacity for otherness" \\
\hline
\end{tabular}

Going into this study, we did expect a high level of global knowledge to already be present among our students because of the large international student population in the SoECS, and the pretest results of this survey showed the mean value of each of the intercultural and global competencies of the students in this class to be:

- "tolerance for ambiguity" $\quad \mu=1.95$

- "respect for otherness" $\quad \mu=2.55$

- "behavioral flexibility" $\quad \mu=3.25$

- "capacity for empathy" $\quad \mu=2.75$

which were in line with our expectations.

The pretest was administered to 32 students in two sections of ETCS 105 that were offered in the fall 2013 semester at the Manhattan campus. The test was administered anonymously, under an approved IRB protocol and the figures above represent the sample mean for each of the four intercultural competencies.

In the ETCS 105 course students are asked to examine various ethical scenarios, which vary in seriousness and difficulty. The students are asked to:

- Identify the "stakeholders" i.e. those people and organizations that will be affected by their decision

- List the issues at stake, and the risks, and consequences of possible actions

- Identify their professional and general ethical responsibilities

- Categorize each of their possible actions as ethically obligatory, prohibited or acceptable

- Select an action

Because there is no simple answer to many of these scenarios, or even many acceptable actions that can be taken, the students gain a "tolerance for ambiguity". They learn that ethical problems do not yield solutions by simply applying a formula or algorithm and that ethical theories and professional codes of conduct often do not provide indisputably correct positions on most issues.

As a result, we believe that those students who complete the course will be more comfortable with ambiguity (i.e. less rigid in their thinking) and have a greater "capacity for empathy".

The ETCS 105 team projects in the areas of robotics, website creation etc., that the students engage in, are intended not only to introduce them to various aspects of a technical career but are meant to foster "behavioral flexibility", and "respect for others" as well. 
That this goal was accomplished was reflected in the post test that was administered during the last week of class. The mean scores in each of the categories of global and intercultural competence increased to:

- “tolerance for ambiguity” $\quad \mu=2.45$

- "respect for otherness" $\quad \mu=2.75$

- "behavioral flexibility” $\quad \mu=3.55$

- “capacity for empathy” $\quad \mu=2.95$

The t-Test is a widely used statistical test for the significance of the difference between the means of two independent samples. In this case we want to determine whether or not the changes in the student's pre and post test scores can be attributed, with a high degree of reliability, to the ethics scenarios and team projects they engaged in. Statistical significance is determined by the size of the difference between the group averages, the sample size, and the standard deviations of the groups. Table 3 illustrates the $\mathrm{p}$ values for each of the categories of global and intercultural competencies with the number of degrees of freedom $\mathrm{df}=60$ :

Table 3: t=Test Results

\begin{tabular}{|l|c|c|c|}
\hline \multicolumn{1}{|c|}{ Competencies } & Pre-test $\mu$ & Post-test $\mu$ & $\begin{array}{c}\text { Significance of Difference of the } \\
\text { Means }\end{array}$ \\
\hline "tolerance for ambiguity" & 1.95 & 2.45 & $\mathrm{p}<.01$ \\
\hline "respect for otherness" & 2.55 & 2.75 & $\mathrm{p}<.025$ \\
\hline "behavioral flexibility" & 3.25 & 3.55 & $\mathrm{p}<.01$ \\
\hline "capacity for empathy" & 2.75 & 2.95 & $\mathrm{p}<.025$ \\
\hline
\end{tabular}

2. EENG 275, 315, 360, 403 “Electronic Labs I, II, III, IV” ABET SO “ $\mathrm{d}$ ” is strongly linked to their ability to:

- work with others, respect alternative perspectives,

- to remain non-judgmental when disagreeing with others and

- seek conflict resolution.

Therefore the ECE department believes that the four Electronic Labs are where students learn some of the most important aspects of a global perspective, (i.e., to employ effective and appropriate interaction and teamwork with people) by demonstrating respect for one another in the labs which is in line with the rubric for ABET SO and which is documented for each Electronics Lab in the "Teamwork Rubric Template", used by the "Lab Team Captain" at least five times during the semester (see Appendix B).

While the data from the FCARs for these Electronic labs will be evaluated at the spring Faculty Assessment meeting which will take place at the end of the spring 2014 semester, in the fall 2013 semester the ECE department offered Electronic Labs II and IV.

To gain some insight, as to whether or not the students taking EENG 403 during the fall 2013 semester have a greater global/cultural competency than those students who took the lab prior to the department's efforts to require our engineering graduates to have significant cross-cultural skills we looked at the FCARs for EENG 403 during the fall 2011 semester. 
Once again, we used the t-Test to determine if the mean scores for ABET SO "d" teamwork on each of these FCARs changed, and in this case we want to determine whether or not the changes in the scores can be attributed, with a high degree of reliability, to the use of the "Teamwork Rubric Template" and the "ECE Lab Guidelines"

The number of students in each class was 24 and the Table 4 below contains the results of the test:

Table 4. t-Test Results for Student Outcome “d” (EENG 403 "Electronics Lab IV)

\begin{tabular}{|c|l|c|c|c|}
\hline Semester & $\begin{array}{l}\text { Electronics } \\
\text { Lab }\end{array}$ & No. of Students & $\begin{array}{l}\text { SO “d” } \\
\text { (Mean) }\end{array}$ & $\begin{array}{l}\text { Variance of } \\
\text { “d” }\end{array}$ \\
\hline Fall 2011 & EENG 403 & 24 & 1.792 & .6067 \\
\hline Fall 2013 & EENG 403 & 24 & 2.083 & .6014 \\
\hline
\end{tabular}

Using these figures for the "Significance of Difference of the Means" we obtained a p value of .002662 which indicates there is a high degree of reliability.

3. IENG 400 "Technology and Global Issues” ABET SO “ $h$ ” to assess their level of alternative perspectives in a societal context with regard to ethical, economic and environmental issues.

This course was introduced for the purpose of assessing ABET SO " $\mathrm{h}$ " using the FCARs as described in section III “The Process” and the course goals as stated in the course outline are:

Making choices is an essential aspect of the scientific method and an inescapable feature of every public debate over scientific or technological issues. The ability to select among alternatives, analyze texts and data, form arguments and make informed decisions is critical for all of us, because we must deal with scientific and technological issues on a daily basis. This course is designed to stimulate and cultivate the ability to consider, evaluate and choose among alternatives.

Each week or two students will consider an issue in science and technology that has currently provoked substantial debate. The issue will be expressed as a single question in order to draw the lines of debate clearly

It should be stressed that the issues presented are still in debate so there is no right or wrong answer. Instead, your essays should demonstrate an understanding of the debate and the reasoning that went into your own conclusions.

The EGMU \{Excellent (3), Good (2), Minimal (1), Unsatisfactory (0)\} score for a class of 34 students was 2.14. This is well above the EGMU score of 1.5, which the department is using as a satisfactory score, since it is equivalent to a " $\mathrm{C}$, Satisfactory" score on the customary A, B, C, D scale of grading student work. 


\section{Conclusion:}

To summarize, if students go through the ECE program, and complete their laboratory classes I to IV, EENG 275, 315, 360 and 403, IENG 400 and EENG 489, 491 the capstone senior design sequence, with the broader interpretation of the ABET SOs a to k to include intercultural and global competency with the consequent course content as described in this paper, then the assessment of the familiar ABET SOs, “c, d, f, h, j, and k”, will demonstrate that engineering programs can indeed educate its graduates to be globally competent engineers even in the absence of international exchange programs.

\section{References:}

1. Dianne J. DeTurris “Assessment Rubric for Global Competency in Engineering Education” Proceedings of the 2012 ASEE PSW Conference

2. G. L. Downey et al “The Globally Competent Engineer: Working Effectively with People Who Define Problems Differently” Journal of Engineering Education, April 2006

3. Engineering Accreditation Committee, Criteria for Evaluating Engineering Programs, ABET Inc, 2013

4. https://www.facebook.com/PathwaysToCleanerProduction/info

5. U.S. Department of State in partnership with NAFSA www.100kstrongamericas.org:

6. www.onlineethics.org.

7. Huber-Kriegler, Lázár and Strange "Mirrors and windows: an intercultural communication textbook" published by the European Centre for Modern Languages, 2003

8. www.psyctherapy.com ToleranceForAmbiguityScale

9. Feuille, Carolyn and Griffiths, Bruce Polaris ${ }^{\circledR}$ Global Leadership Competency Model and $360^{\circ}$ Assessment Survey, 2010

10. Parkinson, Alan (2009) "The Rationale for Developing Global Competence," Online Journal for Global Engineering Education: Vol. 4: Iss. 2, Article 2

\section{Bibliography:}

1. Hunter, W. (2004). Knowledge, skills, attitudes, and experiences necessary to become globally competent. Unpublished dissertation, Lehigh University, Bethlehem, PA

2. Dowell, E., E. Baum, and J. McTague, Green Report: Engineering Education for a Changing World. American Soc. for Engineering Education, 2006

3. National Academy of Engineering, The Engineer of 2020: Visions of Engineering in the New Century, National Academies Press, 2004.

4. Hunter, B., White, G.P., Godbey, G.C., “What Does it Mean to Be Globally Competent?”, Journal of Studies in International Education, Vol. 10, 2006, pp. 267-285.

5. Green, M.F., Olson, C., Internationalizing the Campus: A User's Guide, American Council on Education, Washington D.C.

6. Hammer, M.R., Bennett, M.J., Wiseman, R. "Measuring Intercultural Sensitivity: The Intercultural Development Inventory,” International Journal of Intercultural Relations, Vol. 27, 2003, pp. 421-433

7. Duderstadt, James J. (2008). Engineering for a Changing World: A Roadmap to the Future of Engineering Practice, Research, and Education, 2008. Retrieved from http://milproj.ummu.umich.edu/publications/EngFlex report/download/EngFlex\%20Report

8. Lohmann, Jack R., Rollins, Howard A., \& Hoey, J. Joseph. (2006). Defining, developing and assessing global competence in engineer. European Journal of Engineering Education, 31 (1): 119 - 131

9. Grandin, John M., \& Hirleman, E. Dan. (2009). Educating Engineers as Global Citizens: A Call for Action / A Report of the National Summit Meeting on the Globalization of Engineering Education. Online Journal for Global Engineering Education. Volume 4, Issue 1, Article 1.

10. Kean, Thomas H. \& Hamilton, Lee H. (2008). “We can’t be competitive globally if we lack exposure beyond US borders,” Christian Science Monitor, 12 June 2008.

11. Parkinson, Alan. (2009). The Rationale for Developing Global Competence. Online Journal for Global Engineering Education, 4 (2). 


\section{ECE Team Guidelines}

\section{Appendix A}

- Students will form multidisciplinary teams consisting of 4 members.

- The team will elect one member to be the team captain.

- In addition to the team captain, each member is expected to assume a designated role in the group.

- To maintain a multidisciplinary team, each member will assume a role with expertise from different areas: software development, hardware development, project management etc.

- Each team will work on an independent basis and will be responsible for its own project formulation.

- The primary function of the instructor will be to serve as a mentor to the team.

- The team captain will be responsible for creating a comprehensive laboratory notebook that documents the weekly progress made on the chosen project as well as the collaborative efforts of each of the team members.

- The team captain will be responsible for formulating, writing and presenting the comprehensive proposal of the project.

- The team captain will be responsible for the final project oral presentation and written report.

- The team captain will be responsible for creating and maintaining a web page for these documents.

- Each team member must be prepared for group meetings with clearly formulated ideas and contribute a fair share to the project workload, share credit for success and accountability for team results, share information and provides assistance to/with others and remains non-judgmental when disagreeing with others/seek conflict resolution. 


\section{APPENDIX B}

\section{ECE Lab Team Work Rubric Team Captain Evaluation}

Note: each of the following components will be given a score: E: Excellent (3)

G: Good (2)

M: Minimal (1)

U: Unsatisfactory (0)

Please provide names of the team members you are evaluating and the role they have as a member of a multidisciplinary team.

For each team member, please describe briefly what his/her task was for the week beginning at the date below.

\begin{tabular}{|l|}
\hline Team Name: \\
\hline Member 1 \\
\hline Member 2 \\
\hline \\
\hline Member 3 \\
\hline Date: \\
\hline
\end{tabular}

Team captain - please enter your EGMU score in the Table below

\begin{tabular}{|l|l|l|l|l|}
\hline Main Item & Sub Items & Member 1 & Member 2 & Member 3 \\
\hline $\begin{array}{l}\text { Contribution } \\
\text { to the team }\end{array}$ & $\begin{array}{l}\text { Demonstrates an ability } \\
\text { to conduct literature } \\
\text { research and gather }\end{array}$ & & & \\
\hline
\end{tabular}




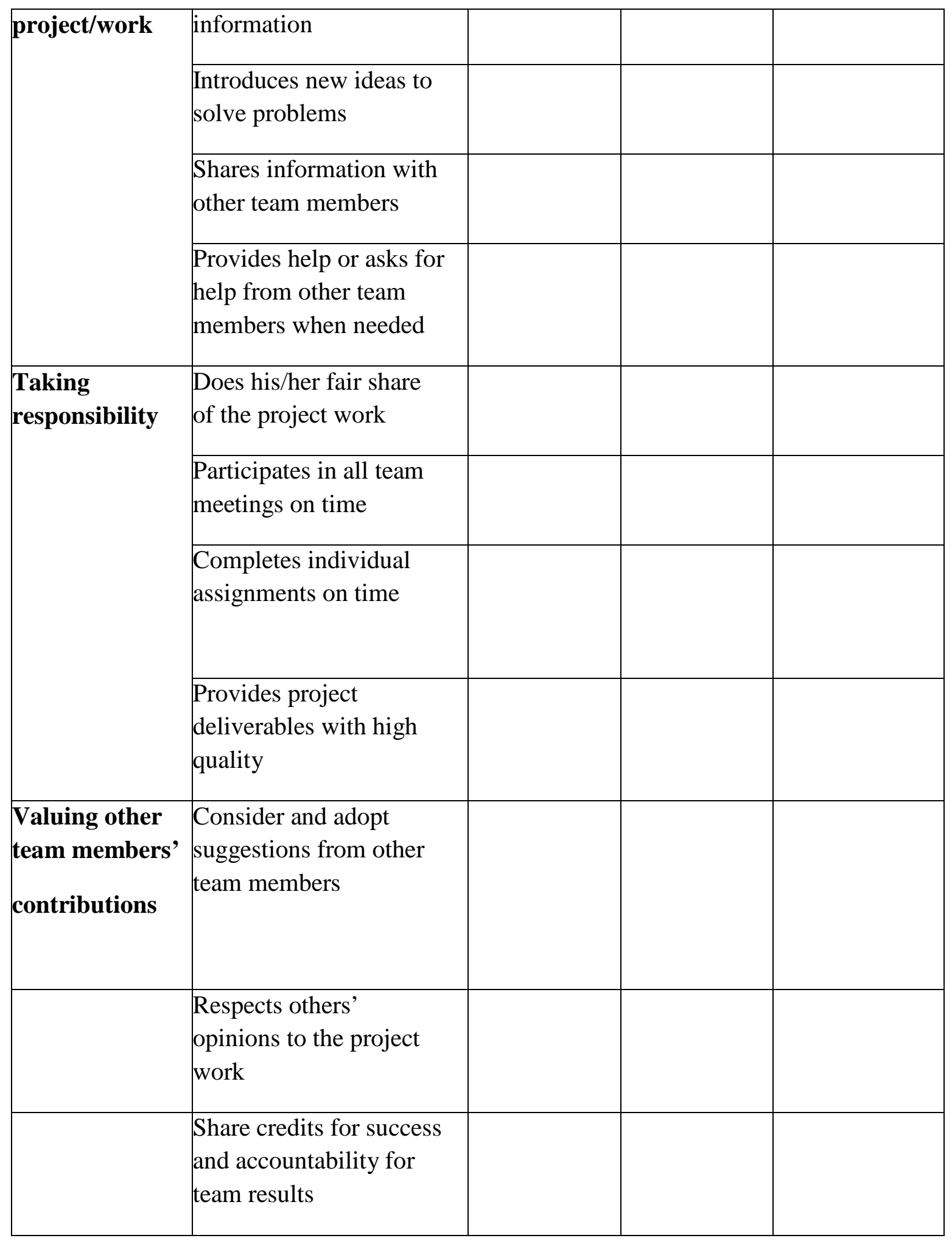




\begin{tabular}{|l|l|l|l|l|}
\hline Total Points & & & & \\
\hline $\begin{array}{l}\text { Comments } \\
\text { (Team Captain) }\end{array}$ & & & & \\
& & & & \\
\hline
\end{tabular}

\section{Appendix C}

The EGMU Vector is obtained using Table 5 as follows:

Table 5 - EGMU Rubrics

\begin{tabular}{|l|l|c|}
\hline EGMU & \multicolumn{1}{|c|}{ Rubric } & Score \\
\hline E - Excellent & $\begin{array}{c}\text { Fully demonstrates/accomplishes } \\
\text { the attributes and behavior in the rubric }\end{array}$ & 3 \\
\hline G - Good & $\begin{array}{l}\text { Mostly demonstrates/accomplishes } \\
\text { the } \\
\text { attributes and behavior in the rubric }\end{array}$ & 1 \\
\hline M - Minimal & $\begin{array}{l}\text { Minimally } \\
\text { demonstrates/accomplishes the } \\
\text { attributes and behavior in the rubric }\end{array}$ & 0 \\
\hline U - Unsatisfactory & $\begin{array}{l}\text { Does not demonstrate/accomplish } \\
\text { the attributes and behavior in the rubric }\end{array}$ & 2 \\
\hline
\end{tabular}




\section{APPENDiX D}

\section{Rubrics for ABET Student Outcomes c, d, f, h, j, k}

ABET Outcome c: an ability to design a system, component, or process to meet desired needs within realistic constraints such as economic, environmental, social, political, ethical, health and safety, manufacturability, and sustainability (an EGMU score of 3)

- Is able to use engineering, computer, and mathematical principles to develop alternative designs taking into consideration economic, health, safety, social, and environmental issues, codes of practice, and applicable laws.

ABET Outcome d: an ability to function on multi-disciplinary teams (an EGMU score of 3)

- Is prepared for group meetings with clearly formulated ideas and contributes a fair share to the project workload

- Shares credit for success and accountability for team results

- Shares information and provides assistance to/with others

- Is able to assume a designated role in the group

- Values alternative perspectives and encourages participation among all team members

- Remains non-judgmental when disagreeing with others/seeks conflict resolution

ABET Outcome f: an understanding of professional and ethical responsibility (an EGMU score of 3)

- Student is familiar with the IEEE and ACM Code of Ethics and the Students' Code of Conduct

- Takes personal responsibility for his/her actions

- Evaluates and judges a situation using facts and a professional code of ethics

- Uses personal value system to support actions, but understands the importance of using professional ethical standards for corporate decisions

ABET Outcome h: the broad education necessary to understand the impact of engineering solutions in a global, economic, environmental, and societal context

(an EGMU score of 3)

- Is familiar with the current trends in the engineering disciplines and the historical aspects of engineering solutions and their impacts

- Is able to evaluate political solutions, or scenarios using a series of different measures e.g., economic, quality of life; number of individuals affected; political ramifications; etc.

- Can demonstrate a personal perspective on the importance of engineering in today's world 
ABET Outcome j: a knowledge of contemporary issues (an EGMU score of 3)

- Has knowledge of current events in society as well as the engineering discipline

- Able to discuss, summarize, and defend major political issues at national, state and local levels:

ABET Outcome k: an ability to use the techniques, skills, and modern engineering tools necessary for engineering practice (an EGMU score of 3)

- Uses computer-based and other resources effectively in assignments/projects

- Maintains current, state-of-the-art abilities in PC use

- Is able to learn and implement process simulation software 